\title{
Evaluation of the Prevalence and Effectiveness of Education on Metered-Dose Inhaler Technique
}

\author{
Kayce M Shealy PharmD BCPS BCACP CDE, Victoria C Paradiso, Megan L Slimmer, \\ Darien L Campbell, and Tiffaney B Threatt PharmD CDE
}

\begin{abstract}
BACKGROUND: The objectives of this study were: (1) to assess the prevalence of and types of education methods provided to participants who use a metered-dose inhaler (MDI), (2) to determine the prevalence of MDI misuse in adults using objective and subjective assessments, and (3) to determine whether any associations exist between the education method and the participant's ability to properly use an MDI. METHODS: Adult participants who had a current or previous history of MDI use were recruited from retail pharmacies and physician offices in Laurens County, South Carolina. Exclusion criteria included the use of an MDI spacer, inability to speak/understand English, or current acute respiratory illness. Participants completed a survey regarding inhaler use and previous education, a subjective checklist assessment by demonstrating use of an MDI, and an objective assessment by using the Aerosol Inhalation Monitor (AIM). RESULTS: Of 100 participants, $25 \%$ reported never having received education about inhaler technique, and $94 \%$ were found to have insufficient MDI technique. No association between the method of education and successful MDI technique with the AIM was identified $(P=.31)$. Participants were less likely to correctly use the AIM if they missed $>3$ steps in the subjective assessment. $(P=.032)$. CONCLUSIONS: Although most participants received inhaler education, inhaler misuse was very common. No associations were found regarding method of education and proper inhaler technique. Key words: metered-dose inhaler (MDI); MDI education; MDI technique; misuse; Vitalograph AIM; objective assessment. [Respir Care 2017;62(7):882-887. (C) 2017 Daedalus Enterprises]
\end{abstract}

\section{Introduction}

The treatment of many respiratory conditions involves the use of medications that are delivered through an inhaler, and metered-dose inhalers (MDIs) are common delivery devices. ${ }^{1,2}$ Many MDI users fail to demonstrate appropriate inhaler technique, despite various educational methods. Participants in a randomized non-crossover trial

The authors are affiliated with the Department of Pharmacy Practice, Presbyterian College School of Pharmacy, Clinton, South Carolina.

This work was supported by the Pharmacy Research Summer Internship and by Small Pharmacy Awards for Research and Collaboration (SPARC) Grant 721210 . The authors have disclosed no conflicts of interest.

Correspondence: Kayce M Shealy PharmD BCPS BCACP CDE, Department of Pharmacy Practice, Presbyterian College School of Pharmacy, 307 North Broad Street, Clinton, SC 29325. E-mail: kmshealy@presby.edu.

DOI: $10.4187 /$ respcare.05246 received MDI technique instruction via one of 4 methods: reading an MDI package insert pamphlet, watching an MDI instructional video developed by the Centers for Disease Control and Prevention, watching a YouTube video about appropriate MDI technique, or receiving pharmacist consultation regarding appropriate MDI technique. ${ }^{3}$ Participants who received pharmacist consultation were more likely to demonstrate correct technique, although only $29.9 \%$ of the 72 participants performed correct inhaler technique after any instruction. Another study utilized a technique checklist in 47 hospitalized subjects with asthma or COPD and found that $73 \%$ of users made at least one critical mistake during MDI administration. ${ }^{4}$ The researchers of this study considered critical steps to include "remove cap, shake well, inhale slowly, actuating once during first half of inhalation, and continue slow and deep inhalation." 4 Noncritical steps included "breathe out normally, keep head upright or slightly tilted, seal lips around mouthpiece, and hold breath for 5 or more seconds." 4 
Although these studies reinforce the importance of assessing participant inhaler technique at MDI initiation and on a regular basis, only subjective assessments of techniques were conducted. ${ }^{3,4}$ Therefore, it is possible that participants who demonstrated appropriate technique according to the checklist may not have actually coordinated

\section{See the Related Editorial on Page 1001}

the inhalation correctly. Only one trial was found to use objective measurements to assess MDI technique. This study evaluated inhaler technique in approximately 2,100 participants with asthma using the Aerosol Inhalation Monitor (AIM) by Vitalograph (Ennis, Ireland)..$^{5}$ This device is designed to assist medical practitioners in objectively assessing a participant's proper inhaler use. Of the nearly 1,300 participants in this study who used an MDI, approximately $85.6 \%$ failed their first assessment using the Vitalograph AIM. After receiving instruction from a trained asthma nurse, subjects repeated the Vitalograph AIM assessment for the second time, and $78.4 \%$ continued to demonstrate poor inhaler technique per the Vitalograph AIM. After a third instruction and attempt, $65.7 \%$ of subjects still failed to produce appropriate inhaler technique. ${ }^{5}$ The study did not collect information from the participants regarding previous inhaler use (ie, duration of inhaler use and extent/method of past MDI education). This uncollected information may be relevant because past MDI training experiences may influence an individual's ability to perform appropriate and consistent MDI technique.

Respiratory guidelines, including the Global Initiative for Chronic Obstructive Lung Disease recommendations (http:// goldcopd.org/global-strategy-diagnosis-managementprevention-copd-2016/, Accessed February 1, 2017), suggest that participants be instructed on proper inhaler technique and also have their technique assessed at each visit. ${ }^{1,2}$ However, there is no specific recommendation regarding the best methods of instruction or assessment. Specifically, MDIs can be more difficult to use appropriately, given the coordination required. Improper use of MDIs has been linked to poorer health and uncontrolled respiratory disease and unfortunately is common. ${ }^{6-9}$ For these reasons, a high priority should be placed on determining the most effective way to counsel and monitor MDI administration.

This study was developed to (1) assess the prevalence of and types of education methods provided to participants who use an MDI, (2) determine the prevalence of MDI misuse in adults using objective and subjective assessments, and (3) determine whether any associations exist between the education method and the participant's ability to properly use an MDI.

\section{QUICK LOOK}

\section{Current knowledge}

Metered-dose inhalers (MDIs) are difficult to use because they require significant coordination. Education and instruction regarding proper use of MDIs are recommended at each visit.

\section{What this paper contributes to our knowledge}

Although inhaler education was provided to most participants, inhaler misuse was prevalent. Misuse of inhalers did not differ based upon method of education received.

\section{Methods}

Participants were recruited from retail pharmacies and physician offices in Laurens County, South Carolina. Consenting participants had to be $\geq 18$ y old and have previously used or currently use an MDI. Individuals were not eligible to participate in the study if they required the use of a spacer, did not speak English, or were currently experiencing an acute respiratory illness. Researchers were trained in technique assessment using a standardized checklist as well as the Vitalograph AIM. This study was approved by Presbyterian College's institutional review board.

Before data collection, pharmacist-directed information brochures describing the study were developed and given to the 7 study sites. Participant information cards were distributed to pharmacies to inform participants of the study for recruitment. Materials for data collection included an informed consent form, participant survey, investigator checklist for assessing participant MDI technique (Table 1), pictorial inhaler chart to help patients identify their inhaler, and one Vitalograph AIM. The Vitalograph AIM consists of an electronic modem that displays the results, rubber tubing that attaches to a removable plastic mouthpiece, and a placebo canister. The manufacturer of the AIM states that the device "measures inspiratory flow, ongoing flow, and breath-holding. A color-coded response indicates the quality of the patient's technique (green for good technique)." A green band is displayed for each of the following: (1) inspiratory flow of between 10 and $50 \mathrm{~L} / \mathrm{min}$; (2) flow of between 10 and $50 \mathrm{~L} / \mathrm{min}$ for $\geq 50 \%$ of the next $3 \mathrm{~s}$; (3) breath-hold at the end of inspiration of $\geq 5 \mathrm{~s}$. The flowhead (dummy pressurized MDI) is calibrated to the instrument. All flows have a tolerance of $\pm 5 \mathrm{~L} / \mathrm{min}$ (personal communication, 2016, Vitalograph). Although the device is reported to validate inhaler technique, specific evidence regarding validation studies was not readily available. However, this device has been used in previous studies to objectively assess inhaler use. ${ }^{5}$ 


\section{Evaluation of MDI Technique Education}

Table 1. Proper Steps for Metered-Dose Inhaler Use

\begin{tabular}{l}
\hline \hline \multicolumn{1}{c}{ Steps for MDI Use } \\
\hline 1. Hold inhaler upright and shake well. \\
2. Breathe out gently. \\
3. Put mouthpiece between teeth without biting and close lips to form \\
a good seal. \\
4. Start to breathe in slowly through mouth and press down firmly on \\
canister. \\
5. Continue to breathe in slowly and deeply. \\
6. Hold breath for about 10 s or as long as comfortable. \\
7. While holding breath, remove inhaler from mouth. \\
8. Breathe out gently away from mouthpiece.
\end{tabular}

Once enrolled, participants completed a 14-question survey. This participant survey asked for demographic information, background of respiratory illness, and pattern of MDI use, as well as history and frequency of inhaler participant education. Participants were asked to identify what methods were utilized by their doctor, pharmacist, or health-care provider during MDI technique training. Participants were not asked to specify the health-care provider responsible for this education (ie, doctor, pharmacist, nurse, respiratory therapist). Additionally, health literacy was assessed using the single-item literacy screener. ${ }^{10}$ Participants who could not recall the name of their inhaler were given the opportunity to identify it using the visual chart depicting available inhalers.

Participants were then asked to demonstrate how to prepare and administer their MDI using a placebo inhaler. The investigators used a standardized checklist adapted from a guide for the proper use of a metered-dose inhaler by the American Society of Health-System Pharmacists (http:// www.safemedication.com/safemed/MedicationTipsTools/ HowtoAdminister.aspx, Accessed May 25, 2016) (see Table $1)$. Any duration of breath-hold was sufficient to complete step 6, and the researchers recorded additional applicable comments regarding the participant's demonstration.

Next, the Vitalograph AIM was used to evaluate MDI technique. Participants were instructed to use the device with a placebo canister as they would typically use their inhaler; no active ingredients were administered to participants. The Vitalograph AIM qualified participant technique in the following areas: inspiratory flow at the start of inspiration, timing of firing of the MDI simulator, inspiratory flow throughout the inspiration, inhalation time, and breath-hold time. Once the inhalation was complete, the device identified technique as good, suboptimal, or failing. The results were recorded and input into Excel for analysis. All participant questions not pertaining to the purposes of this study were referred to a pharmacist or other healthcare professional. No instruction or correction of technique was provided to participants.

Descriptive statistics were used to analyze demographic information. Fisher exact tests were used to analyze nom-
Table 2. Participant Characteristics: Demographic and Pertinent Survey Responses

\begin{tabular}{|c|c|}
\hline Participant Characteristics $(N=100)$ & Percentage \\
\hline \multicolumn{2}{|l|}{ Sex } \\
\hline Male & 39 \\
\hline Female & 54 \\
\hline No report & 7 \\
\hline \multicolumn{2}{|l|}{ Race/ethnicity } \\
\hline White & 72 \\
\hline Black/African-American & 23 \\
\hline Native American & 2 \\
\hline Hispanic or Latino & 1 \\
\hline No report & 2 \\
\hline \multicolumn{2}{|l|}{ Age range, $y$} \\
\hline $18-40$ & 24 \\
\hline $41-64$ & 42 \\
\hline$\geq 65$ & 31 \\
\hline No report & 3 \\
\hline \multicolumn{2}{|l|}{ MDI instructional methods } \\
\hline Never educated & 25 \\
\hline 1 method & 51 \\
\hline 2 methods & 17 \\
\hline$>2$ methods & 7 \\
\hline \multicolumn{2}{|l|}{ Frequency of MDI use } \\
\hline No response & 13 \\
\hline As needed & 34 \\
\hline Daily & 53 \\
\hline \multicolumn{2}{|l|}{ Current vs past MDI use } \\
\hline Current & 75 \\
\hline Past & 25 \\
\hline \multicolumn{2}{|l|}{ Reason for MDI prescribed } \\
\hline No response & 6 \\
\hline Asthma & 36 \\
\hline COPD & 28 \\
\hline Asthma and COPD & 4 \\
\hline Acute illness & 26 \\
\hline \multicolumn{2}{|l|}{ Assistance reading health literature } \\
\hline Never/rarely & 77 \\
\hline Sometimes/often & 19 \\
\hline Always & 4 \\
\hline
\end{tabular}

inal data. All analyses were completed in Excel 2010 (Microsoft, Redmond, Washington) or SAS 9.4 (SAS Institute, Cary, North Carolina).

\section{Results}

A total of 100 participants were enrolled in the study; however, one participant declined use of the Vitalograph AIM. Therefore, participant characteristics and subjective assessment reflect 100 participants, whereas objective measurement reflects 99 participants. Participant characteristics are provided in Table 2. Participants were mostly white 


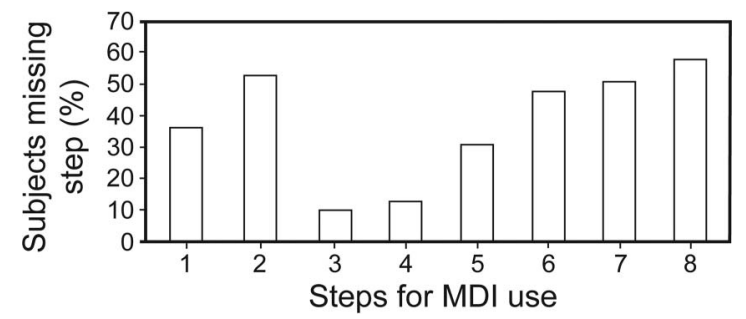

Fig. 1. Subjective metered-dose inhaler (MDI) technique assessment. Shown is the percentage of subjects who missed each numerical step.

females with an average age of $53 \mathrm{y}$. Seventy-five percent of participants currently used an MDI, and 53\% of these participants reported daily use. The majority of participants were prescribed their MDI for asthma (36\%) or COPD management (28\%). Twenty-six percent of participants reported use of an MDI due to acute illness. Seventy-seven percent of participants reported never or rarely needing assistance reading health literature (ie, instructions, pamphlets, or other written material from the doctor or pharmacy).

Approximately $25 \%$ of participants reported having never received instruction on proper MDI technique. Of the remaining participants who reported receiving instruction, verbal communication (55\%) and demonstration (47\%) were the most common instructional methods employed. Only a few participants reported that they received instruction via video $(7 \%)$ or written handouts $(4 \%)$. In addition, almost one fourth of participants reported having received instruction through multiple methods.

Subjective MDI technique assessment revealed that a majority of participants missed steps 2,7 , and 8 of the checklist, as shown in Figure 1. Specifically, only 30\% correctly completed steps $1-3,36 \%$ completed steps 4-6, and 33\% completed steps $3-6$. It should be noted that only $15 \%$ of participants correctly completed each step of the checklist.

Objective measurement of MDI technique indicated that insufficient MDI technique existed among 94\% of MDI users (Fig. 2). Only $6 \%$ of participants achieved good MDI technique results via the Vitalograph AIM. Of those with insufficient MDI technique, $27 \%$ failed to fire the canister appropriately, $27 \%$ performed an inspiratory rate that was too fast, and $40 \%$ demonstrated an inhalation time and/or breath-hold that was too short.

There was no association found among method of MDI instruction received and successful MDI administration per the Vitalograph AIM $(P=.31)$ (Fig. 3). However, the number of checklist steps missed significantly impacted successful MDI administration according to the Vitalograph $\operatorname{AIM}(P=.032)$ (Fig. 4). All individuals who missed $>3$ steps of the checklist were unable to achieve good Vitalograph AIM results. There was no critical step identified that participants with a successful technique per the objective assessment completed compared with those without a successful technique. In addition, only $13 \%$ of those who completed the subjective assessment completely (ie, missed 0 steps) achieved "good" on the objective assessment.

Participants who used their MDI daily as opposed to "as needed" did not demonstrate better technique per objective assessment. Half of participants who achieved good AIM results reported using their inhaler as needed. No association was found between health literacy and a person's ability to use an MDI effectively $(P=.98)$. Those who have adequate health literacy are as likely to misuse their MDI as those who have low health literacy.

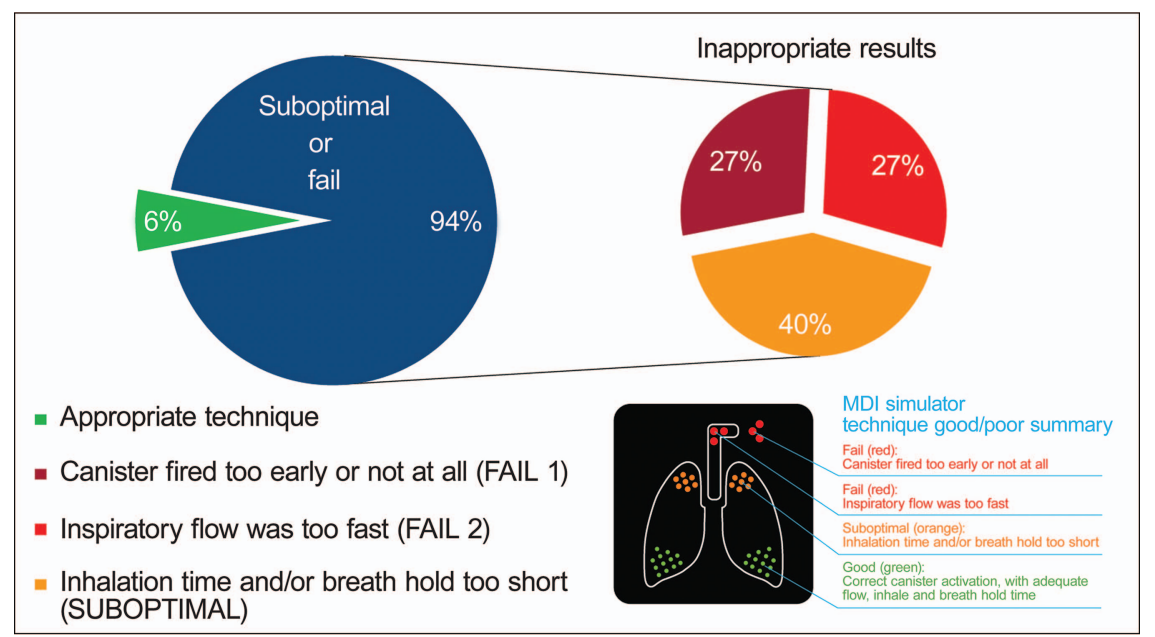

Fig. 2. Objective metered-dose inhaler (MDI) technique assessment. The primary pie chart (left) illustrates $6 \%$ of participants who demonstrated appropriate MDI technique, compared with $94 \%$ who did not. The expanded pie chart indicates the breakdown of results as reported with the Vitalograph Aerosol Inhalation Monitor (AIM). 


\begin{tabular}{l|cccccc}
\hline $\begin{array}{l}\text { Method } \\
\text { of } \\
\text { education }\end{array}$ & Fail (1) & Fail (2) & Alm result \\
\hline $\begin{array}{l}\text { Verbal } \\
\text { communication }\end{array}$ & 4 & 9 & 12 & 3 & Good & Total $P$-value \\
\hline $\begin{array}{l}\text { Demonstration } \\
\text { Combination }\end{array}$ & 8 & 5 & 9 & 1 & 22 & \\
No Education & 4 & 5 & 8 & 0 & 24 & \\
\hline Total & 27 & 27 & 39 & 6 & $99^{*}$ & .31 \\
\hline
\end{tabular}

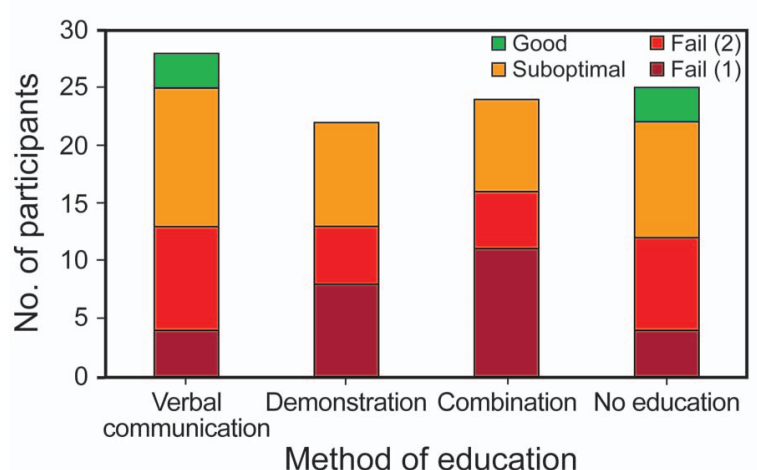

Fig. 3. Vitalograph Aerosol Inhalation Monitor (AIM) result versus method of education. Shown is a comparison of the Vitalograph AIM result with method of metered-dose inhaler education received. * One participant refused to complete the Vitalograph AIM.

\begin{tabular}{|c|c|c|c|c|c|}
\hline \multirow{2}{*}{$\begin{array}{l}\text { No. of } \\
\text { steps } \\
\text { missed }\end{array}$} & \multicolumn{5}{|c|}{ AIM result } \\
\hline & Fail (1) & Fail (2) & Suboptimal & Good & Total $P$-value \\
\hline 0 & 1 & 6 & 6 & 2 & 15 \\
\hline 1 to 3 & 8 & 13 & 19 & 4 & 44 \\
\hline 4 to 6 & 17 & 8 & 13 & 0 & 36 \\
\hline 7 to 8 & 1 & 0 & 1 & 0 & 2 \\
\hline Total & 27 & 27 & 39 & 6 & .032 \\
\hline 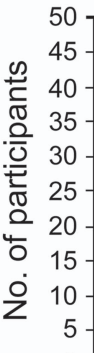 & & & & & $\begin{array}{l}\text { G Good } \\
\text { Q Suboptimal } \\
\text { Q Fail (2) } \\
\text { Q Fail (1) }\end{array}$ \\
\hline & 0 & ${ }^{1}$ & $\begin{array}{l}\text { o } 3 \\
\text { of steps }\end{array}$ & $\begin{array}{l}\text { to } 6 \\
\text { issed }\end{array}$ & 7 to 8 \\
\hline
\end{tabular}

Fig. 4. Vitalograph Aerosol Inhalation Monitor (AIM) result versus missed steps. Shown is a comparison of the Vitalograph AIM result with the number of steps missed while completing the checklist. * One participant refused to complete the Vitalograph AIM.

\section{Discussion}

Although a significant association was not found between method of education and objective assessment results, it is worth noting that $25 \%$ of participants reported that they had never received instruction on how to use their MDI. Respiratory guidelines recommend inhaler education as part of standard practice, and reasons for not educating patients who receive MDIs should be addressed..$^{1,2}$ If more participants in this study had received recommended instruction, the number of successful results using the objective assessment may have been higher. Although it is difficult to extrapolate to the general population, it does bring to light that a significant portion of the population may not be educated or receive any inhaler instruction before use. A recent meta-analysis ${ }^{8}$ also confirms that education and training, and perhaps even newer approaches to education, are needed to improve proper inhaler use.

There was an association between subjective steps missed and successful objective MDI administration. Participants who demonstrated placing the mouthpiece between teeth without biting and closing lips to form a good seal and breathing in slowly through the mouth and pressing down firmly on the canister were more likely to successfully coordinate breathing and actuation of the canister on objective assessment and achieve a good objective result. Those who failed to demonstrate holding breath for about $10 \mathrm{~s}$ or as long as comfortable, while holding breath removing inhaler from the mouth, and breathing out gently away from the mouthpiece were more likely to achieve a suboptimal result. This is expected because suboptimal technique is reported when inhalation time and/or breathhold is too short. Overall, comparison of the results of the subjective checklist assessment with performance in the objective assessment confirms previous findings that MDIs may be more difficult to use given the coordination and timing required.4-6,8,9 In addition, the overall incidence of misuse ( $85 \%$ per subjective; $94 \%$ per objective) is similar to what has been found in previous studies. ${ }^{4-6,8,9}$ This study's use of objective evaluation may provide confirmation to previous studies conducted using only subjective evaluation.

There also appears to be a correlation between the number of missed subjective steps and appropriate MDI technique measured by the ability to perform the objective assessment successfully. Those who missed $>3$ steps were less likely to use their MDI correctly and consequently are expected to receive reduced benefit from it. These results suggest that appropriate administration may be sufficiently assessed by the participant's ability to demonstrate technique using a checklist. Although objective assessment is useful, this study reinforces that assessment using a checklist can achieve similar results. Time to assess using either method was not captured, but both methods were able to be completed relatively quickly. The availability of newer inhaler devices, such as soft-mist inhalers, may also provide professionals the opportunity to select an easier device for use. However, little is known about whether these newer devices result in better management. 
Limitations to this study exist. Given that the survey was completed by the participant, there is potential for inaccurate survey answers because some participants may not recall all MDI education interactions. There is no evidence in the literature describing the actual validity of the Vitalograph AIM. However, observations from the study indicate that if a patient can successfully perform the objective measurement, the critical steps of the subjective assessment will also be appropriately completed. Additionally, this study included participants who had any previous MDI use. Some participants acknowledged that it had been $>1$ y since their last MDI dose. It was expected that participants who had not used their MDI recently might have poorer technique. However, it can be argued that appropriate MDI technique education should be effective enough to withstand periods without MDI use. Three researchers utilized the standardized checklist, and at least 2 researchers were present at each assessment. A potential limitation is that investigators could have perceived and graded participants differently, because inter-rater reliability was not assessed. However, these researchers were all provided extensive training in MDI pharmacotherapy and technique. Another limitation of this study is the small sample size and the restriction of participant recruitment to Laurens County, South Carolina. This may not be representative of the broader population. Last, only a small percentage of patients were able to demonstrate appropriate inhaler technique. This limits the ability to draw definitive conclusions as to specific reasons certain patients are able to use inhalers properly.

\section{Conclusions}

Although instruction on inhaler technique is encouraged, not all patients may receive education on device use. The education that is provided, however, may be insufficient to ensure proper technique. Assessing inhaler technique objectively is helpful, but subjective assessments by providers may quickly and accurately identify patients with poor inhaler technique. Further studies are needed to de- termine the best instructional techniques for participants regarding these steps to ensure proper MDI use.

\section{ACKNOWLEDGMENTS}

We thank Dr Romero-Sandoval (Director of Research at Presbyterian College School of Pharmacy and coordinator of the Pharmacy Research Summer Intern Program; Dr Jun Wu for help with data analysis; and the 7 pharmacies and clinics that allowed participant recruitment.

\section{REFERENCES}

1. Expert panel report 3: guidelines for the diagnosis and management of asthma. Bethesda, Maryland: National Institutes of Health, National Asthma Education and Prevention Program; 2007. NIH Publication No. 08-4051. http://www.nhlbi.nih.gov/guidelines/asthma/ asthgdln.pdf. Accessed September 1, 2016.

2. Laube BL, Janssens HM, de Jongh FHC, Devadason SG, Dhand R, Diot $\mathrm{P}$, et al. What the pulmonary specialist should know about the new inhalation therapies. Eur Respir J 2011;37(6):1308-1331.

3. Axtell S, Haines S, Fairclough J. Effectiveness of various methods of teaching proper inhaler technique: the importance of pharmacist counseling. J Pharm Pract 2016;30(2):195-201.

4. Al Ammari M, Sultana K, Yunus F, Al Ghobain M, Al Halwan SM. A cross-sectional observational study to assess inhaler technique in Saudi hospitalized patients with asthma and chronic obstructive pulmonary disease. Saudi Med J 2016;37(5):570-574.

5. Hardwell A, Barber V, Hargadon T, McKnight E, Holmes J, Levy ML. Technique training does not improve the ability of most patients to use pressurised metered-dose inhalers (pMDIs). Prim Care Respir J 20(1)11;20:92-96.

6. Giraud V, Roche N. Misuse of corticosteroid metered-dose inhaler is associated with decreased asthma stability. Eur Respir J 2002;19(2): 246-251.

7. Levy ML, Hardwell A, McKnight E, Holmes J. Asthma patients' inability to use a pressurised metered-dose inhaler (pMDI) correctly correlates with poor asthma control as defined by the Global Initiative for Asthma (GINA) strategy: a retrospective analysis. Prim Care Respir J 2013;22(4):406-411.

8. Sanchis J, Gich I, Pedersen S, Aerosol Drug Management Improvement Team (ADMIT). Systematic review of errors in inhaler use: has patient technique improved over time? Chest 2016;150(2):394-406.

9. Pothirat C, Chaiwong W, Phetsuk N, Pisalthanapuna S, Chetsadaphan $\mathrm{N}$, Choomuang W. Evaluating inhaler use technique in COPD patients. Int J Chron Obstruct Pulmon Dis 2015;10:1291-1298.

10. Morris NS, MacLean CD, Chew LD, Littenberg B. The single item literacy screener: evaluation of a brief instrument to identify limited reading ability. BMC Fam Pract 2006;7:21.

This article is approved for Continuing Respiratory Care Education credit. For information and to obtain your CRCE

(free to AARC members) visit

www.rcjournal.com

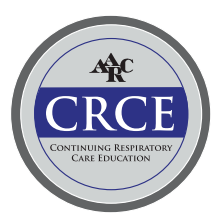

